\title{
A CONSTRUÇÃO DE UMA AGENDA PARA AS QUESTÕES DE GÊNERO, DESASTRES SOCIOAMBIENTAIS E DESENVOLVIMENTO
}

\author{
Rosana de Carvalho Martinelli Freitas \\ Universidade Federal de Santa Catarina
}

\begin{abstract}
Resumo: Este artigo' ${ }^{1}$ tem como objetivo discutir questões relacionadas a desenvolvimento, desastres socioambientais e gênero, as quais, por estarem inscritas no debate contemporâneo brasileiro, constituem elementos que devem pautar pesquisas e estratégias de ação. Apresenta a relação entre gênero, classe, raça/etnia e desastres socioambientais, examinando conceitoschave sobre desenvolvimento, meio ambiente e igualdade no contexto das políticas econômicas recentes. Reflete sobre a situação das mulheres inseridas em uma situação de subalternidade na sociedade capitalista, que sofrem as consequências dos desastres socioambientais. Conclui com sugestões para a inclusão nesses processos do enfoque de gênero na elaboração de agendas de pesquisas e de ação.
\end{abstract}

Palavras-chave: natureza; sociedade; desenvolvimento; desastres; mulheres.

\section{Introdução}

As inundações, incêndios, terremotos, deslizamentos de terra, erupções vulcânicas, furacões, tornados, tsunamis, tempestades tropicais, secas, entre outros fenômenos naturais, apontam para a suscetibilidade de situações às quais o ser humano está exposto. Podem constituir catástrofes, desencadeando um processo social, precipitado por eventos ambientais, mas baseado em relações sociais e econômicas e em padrões de desenvolvimento históricos.

O interesse pelo meio ambiente tem se intensificado nas três últimas décadas devido ao gradual esgotamento dos recursos naturais renováveis e não renováveis. O crescimento e a concentração da população, a superexploração e o inadequado manejo dos recursos

Copyright ( $\odot 2010$ by Revista Estudos Feministas.

' Resultado parcial da pesquisa "Situações de desastres, novos desafios ao trabalho interdisciplinar", apoiada pela FAPESC 
naturais provocam a degradação ambiental dos ecossistemas e estão causando frequentes e crescentes catástrofes. Situações estas preocupantes, porque ultrapassam as propostas de soluções em curso, remetendo a um processo que implica a elaboração e a implementação de agendas de pesquisas e de ações consistentes no que diz respeito ao tema.

Esse recente aumento da atenção para os efeitos dos desastres socioambientais decorrentes, em sua maioria, da imbricada relação entre sociedade e natureza expressase na emergência de movimentos ambientalistas, em conferências e acordos internacionais que têm gerado diferentes perspectivas teóricas e ações políticas. Expressa-se, também, em pesquisas internacionais que, no âmbito das ciências sociais e sociais aplicadas, direcionam-se a aspectos relativos a gênero e desastres socioambientais. ${ }^{2}$ Contudo, o tema não é recorrente nas produções teóricas brasileiras.

Pela procedência desse tema, justifica-se o interesse em introduzir elementos que permitam indicar a importância de fatores como classe, raça/etnia e gênero, que repercutem sobre as mulheres inseridas no processo de prevenção e resposta às situações de desastres socioambientais. Tal preocupação visa subsidiar a elaboração de uma agenda de pesquisa e de ação que proporcione às questões apresentadas ultrapassarem a condição de tema periférico para serem incorporadas pela sociedade como prática, avançando para além dos discursos bem construídos ou das intenções registradas nos documentos oficiais.

Inicialmente, apresenta-se a relação entre gênero e situações de desastres socioambientais, e seus efeitos sobre as mulheres. Na seção seguinte, recupera-se a discussão de conceitos-chave dentro da análise sobre desenvolvimento, meio ambiente e igualdade. Por fim, são apresentadas algumas sugestões para a inclusão do enfoque de gênero em futuras agendas de pesquisa e de ação que objetivem melhor conhecer e apreender os múltiplos e imbricados aspectos relacionados à inserção das mulheres nesse processo.

\section{Os desastres, as situações das mulheres e os caminhos para a construção de uma agenda de pesquisa e de ação}

Em face das questões socioambientais, pela primeira vez, no Rio de Janeiro, em 1992 , os governos se reuniram e concordaram em combater a mudança climática. Durante a reunião, os líderes criaram a Convenção-Quadro das Nações Unidas sobre a Mudança do Clima (Cqnumc ou Unfccc, sigla em inglês). Seu artigo $3^{\circ}$ assim estabelece:

As Partes Contratantes devem proteger o sistema climático para benefício das gerações presentes e futuras da humanidade, com base na equidade e de acordo com as suas responsabilidades comuns, mas diferenciados e com as respectivas capacidades. Assim, as Partes constituídas por países desenvolvidos devem tomar a liderança no combate à alteração climática e aos seus efeitos adversos. ${ }^{3}$

Concomitantemente, foi durante a Década Internacional para Redução de Desastres Naturais (1990) que as mulheres e as crianças foram identificadas como 'as chaves para a prevenção'. Nos anos seguintes, as mulheres organizaram-se para encontros e conferências

\footnotetext{
${ }^{2}$ Entre os/as pesquisadores/as destacam-se Alicia H. Puleo; Cristina Segura e María Luisa Cavana; Elaine Enarson; e Carmen Díaz de Rivera.

${ }^{3}$ ONU, Convenção-Quadro das Nações Unidas sobre a Mudança do Clima, Brasil, 1992.
} 
sobre esses temas, em vários países e cidades. ${ }^{4}$ Os resultados dessas iniciativas levantaram novas questões para os planejadores, pois a análise das catástrofes, 'através dos olhos das mulheres', identificou lacunas, apresentou críticas ao sistema jurídico-institucional e trouxe o gênero para o nível central, como um importante componente para a prevenção e a intervenção em situações de desastres socioambientais.

No entanto, como sinalizado por Sue Amstrong, ${ }^{5}$ as mulheres não estão representadas na Unfecc ou no Protocolo de Quioto. ${ }^{6}$

Não é necessário mais do que uma busca simples na Convenção-Quadro das Nações Unidas sobre Mudança do Clima e no Protocolo de Kyoto, dois grandes tratados sobre os esforços globais de combate às alterações climáticas, para descobrir que as palavras 'gênero' e 'mulheres' não são mencionadas em nenhum deles.

Assim, apreendendo que os impactos decorrentes das relações sociedade e natureza não atingem homens e mulheres da mesma forma, pois os interesses e as necessidades das mulheres não têm sido significativamente incluídos na agenda governamental e de diferentes instituições, apresentar-se-á, nesta seção, elementos que justificam a construção de uma agenda de pesquisa e de ação com uma abordagem alternativa que vincule justiça (social, ambiental, econômica), gênero e desenvolvimento, visando à conservação do meio ambiente e também à prevenção de desastres socioambientais.

As relações de gênero e os desastres socioambientais são socialmente construídos sob a influência de fatores econômicos, políticos, culturais, sociais e sob condições geográficas complexas que refletem condições singulares e particulares para as mulheres e para os homens, a depender das condições de classe, raça/etnia e gênero.

Em dezembro de 2007, quatro instituições internacionais reuniram-se com ministros de meio ambiente e líderes, na Conferência das Nações Unidas sobre Mudança Climática, em Bali, ${ }^{8}$ para afirmar, pela primeira vez, na história da Convenção sobre Mudança Climática das Nações Unidas, que uma coalizão mundial de mulheres esboçou manifestos sobre as perspectivas das mulheres e do gênero a respeito das problemáticas mais urgentes negociadas na Convenção. ${ }^{9}$

Como resultado da reunião e organização das mulheres, os países signatários e a Secretaria da Comissão de Mudança Climática das Nações Unidas foram desafiados a reconhecer que as mulheres são poderosas agentes de mudança e que sua total participação nas políticas e iniciativas de adaptação e mitigação do clima é crucial. Portanto, torna-se imprescindível garantir que as mulheres e os especialistas em gênero participem, de maneira qualificada e crítica, de todas as decisões relacionadas com mudança climática, haja vista a predominância de produções teóricas que têm privilegiado a inserção das mulheres no processo de minimização dos desastres socioambientais.

\footnotetext{
${ }^{4}$ Como: Austrália (1995); Paquistão - Duryog Nivaran (1996); Bruxelas (1996); Washington, DC (InterAction, 1998); British Columbia (1998); Miami (2000); e Bangladesh (2000).

${ }^{5}$ Sue ARMSTRONG, 2001.

6 O Protocolo de Quioto (2005) foi ratificado por 120 nações que se comprometeram a reduzir as emissões de gases de efeito estufa, principalmente de carbono, para 5,2\% abaixo dos níveis de 1990, até 2007.

${ }^{7}$ ARMSTRONG, 2001, p. 1.

${ }^{8}$ O encontro em Bali foi a $13^{\circ}$ reunião anual do grupo da ONU, chamado de Convenção das Partes (COP, na sigla em inglês). Esse grupo é a instância decisória da "Conferência da Organização das Nações Unidas sobre Mudança Climática", nome dado ao tratado que surgiu depois da "Rio 92", a conferência da ONU que reuniu líderes do mundo todo no Rio de Janeiro em 1992 para discutir as mudanças no clima.

${ }^{9}$ Para mais informações sugere-se consultar. Boletim Movimento Mundial pelas Florestas Tropicais. Disponível em: <http://www.wrm.org.uy > . Acesso em: 12 maio 2010.
} 
Kellie Tranter ${ }^{10}$ demonstrou que mais mulheres do que homens morrem como efeito direto e indireto dos desastres socioambientais. Assim é que $90 \%$ das 140.000 vítimas do ciclone que açoitou Bangladesh, em 1991, foram mulheres; igualmente, mais mulheres do que homens morreram durante a onda de calor de 2003, na Europa; e o tsunami de 2006 no Sri Lanka matou de três a quatro mulheres para cada homem. Quais seriam as razões? Por que as mulheres estão mais sujeitas do que os homens às consequências dos desastres?

A partir dessas questões e da concepção de que "o homem é natureza", ${ }^{1}$ serão elencados alguns elementos que devem ser considerados na abordagem do tema.

As condições econômicas, sociais e culturais de cada pessoa podem aumentar os efeitos dos desastres socioambientais, expondo-a a novos danos e perdas como, por exemplo, em relação ao emprego. Portanto, não se trata simplesmente de uma questão 'técnica', mas social, que expõe a capacidade da pessoa, do bairro, do município, do país, de se antecipar, planejar, sobreviver e recuperar-se dos efeitos devastadores desses eventos.

A globalização econômica contemporânea, por exemplo, aumenta a insegurança das mulheres, que, muitas vezes, são chefes de família, quanto ao emprego, ao salário e, além disso, sofrem com os cortes decorrentes do ajustamento estrutural, os quais repercutem na quantidade e qualidade dos serviços sociais por elas acessados. O processo de migração urbana ${ }^{12}$ também reflete nas condições de vida inseguras nos grandes centros urbanos, porque as mulheres e suas famílias ficam mais expostas à poluição, às enchentes e aos deslizamentos. Ainda, no âmbito da degradação ambiental, são inúmeros os efeitos da seca sobre as mulheres agricultoras e/ou do desmatamento sobre aquelas que dependem da lenha.

Todavia, as situações de desastres socioambientais também afetam os homens. Na divisão sexual do trabalho, são eles que assumem as atividades de resgate, enfrentam situações adversas, ficam submetidos às normas de masculinidade, que podem podem limitar sua capacidade de pedir a ajuda necessária.

As relações entre homens e mulheres são forças poderosas em cada cultura. A maneira como essas relações são definidas cria diferenças nos papéis e nas responsabilidades dos homens e das mulheres; também determinam desigualdades no acesso e no controle sobre os recursos (herdar a terra ou obter crédito do banco) e poderes de decisão (ocupar um assento em conselhos comunitários e/ou de direito e comissões). O efeito combinado dessas diferenças e das desigualdades significa que mulheres e meninas, homens e meninos enfrentam diferentes tipos e níveis de exposição aos impactos e às consequências dos desastres socioambientais. A adoção de comportamentos e estereótipos dos homens e das mulheres pode contribuir para aumentar as diferenças de gênero, às vezes, com consequências devastadoras. Um exemplo da influência de valores culturais, durante um desastre, é o de Sri Lanka. Naquele país, nadar e subir em árvores são atividades ensinadas, principalmente, aos meninos. O preconceito social reduz a possibilidade de as meninas e as mulheres desenvolverem essas habilidades, diminuindo consideravelmente suas chances de sobrevivência nas inundações.

Outro exemplo, em Blumenau, município ao Sul do Brasil, durante as enchentes, acompanhadas de deslizamentos, em 2008, algumas mulheres foram encontradas mortas, com os filhos em seus braços. Alguns relatos pessoais de sobreviventes descrevem mães

10 TRANTER, 2008, p. 1

"Para mais informações, sugere-se a leitura dos Manuscritos Econômicos Filosóficos, escritos por Karl Marx, em 1844 (MARX, 1987, p. 11).

12 Russel SCOT, 2007. 
abraçadas com seus bebês dentro das casas soterradas e outras presas aos troncos das árvores para resistirem às enxurradas. Essas mulheres, imbuídas de suas responsabilidades enquanto mães e cuidadoras, utilizaram muito tempo para socorrer seus filhos, o que comprometeu a desocupação das casas, sendo insuficiente o tempo para conseguirem um lugar para se abrigarem.

Juntamente com aspectos culturais, a desigualdade de classe existente e manifesta, inclusive, na condição de renda potencializa o impacto dos desastres socioambientais sobre as mulheres e suas famílias. Além do mais, os desastres socioambientais ocasionam uma sobrecarga de trabalho para as mulheres, tanto no momento que antecede o evento como durante e depois. Os sintomas de estresse pós-traumático têm incidência maior entre as mulheres, e também são maiores as taxas de violência sexual e doméstica contra mulheres e meninas em contexto de desastres.

Devido ao fato de as mulheres serem as principais responsáveis pelas responsabilidades domésticas, tais como cozinhar, cuidar dos filhos, dos idosos ou de pessoas da família com deficiência, elas, como cuidadoras, são livres para migrarem em busca de um trabalho após um desastre. Efetivamente, os homens migram em maior número e com mais frequência, deixando um grande número de mulheres como chefes de família.

Durante uma catástrofe, a residência é frequentemente destruída. Assim, muitas famílias são obrigadas a se deslocar para albergues, abrigos e/ou moradias provisórias. Embora sejam denominadas provisórias, a permanência das famílias nesses locais prolongase por um período significativo, como já evidenciado em Rosana Freitas e Cristiane Marques. ${ }^{13}$ No caso das enchentes do Vale do Itajaí, em 2008, até o presente momento ainda há 250 famílias vivendo em abrigos. São locais inadequados, com banheiros e cozinhas de uso coletivo, que aumentam a carga de tarefas domésticas das mulheres e reduzem sua liberdade de movimento e de ação. Dificultam a busca por fontes alternativas de renda, comprometendo sua posição como coprovedoras financeiras da família. Vivendo nesses abrigos temporários, as mulheres-mães também percebem que aumentam as probabilidades de seus filhos serem vítimas de violência sexual.

A imagem do sofrimento de mulheres e crianças durante um desastre é muito popular na mídia. Mas o que a mídia não mostra são as mulheres como uma parte vital dos esforços de resposta aos desastres, atuando dentro de seus papéis ou transcendendo-os. Igualmente como apontado por Freitas e Marques, legislações públicas, atitudes e comportamentos de técnicos e profissionais revelam preconceitos; reforçam uma visão essencialista sobre a mulher e reiteram a divisão sexual do trabalho no processo de resposta às situações de desastres socioambientais.

Na presente década, novas abordagens vêm apresentando a necessidade de se trabalhar em conjunto para prevenir eventos que possam vir a ser trágicos e destrutivos. Tais enfoques, baseados na análise de gênero, indicam a importância de se valorizar o conhecimento e as habilidades das mulheres, até agora negligenciados, em contextos considerados como de ameaça e risco.

Uma abordagem, a partir de uma perspectiva de gênero em situações de desastres socioambientais, não se restringe a privilegiar a participação das mulheres no pósacontecimento, celebrando suas atividades compensatórias junto a perdas e danos ocorridos. Esse tipo de abordagem somente se justifica quando as relações de classe, as relações sociais entre homens e mulheres, são reconhecidas como uma força presente na vida das pessoas, em cada cultura, que produz e reproduz diferenças e desigualdades. $O$ tipo de inserção, de percepção, os interesses econômicos e sociais das mulheres e dos

\footnotetext{
${ }^{13}$ FREITAS E MARQUES, 2010.
} 
homens reforçam, implicitamente ou não, um modelo de 'desenvolvimento', e também influenciam nas relações sociedade/meio ambiente e nas consequências decorrentes dessa relação, expressas através dos perigos, dos desastres socioambientais.

A maioria dos problemas de gênero não é decorrente de costumes culturais ou religiosos e pode se transformar, mediante a intervenção política que proporcione capacidade para o pensamento crítico e contribua para a mudança dos 'papéis' e comportamentos atribuídos às mulheres, os quais, como já mencionado, são construções sociais. Esse processo educacional é complexo, pois não será possível esperar que decorra do interesse dos países considerados desenvolvidos, quando justamente são estes parte dos problemas, uma vez que exacerbam suas decisões e ações em prol de um modelo de desenvolvimento orientado por uma racionalidade destrutiva.

\section{O desenvolvimento, os desastres socioambientais e o desafio da igualdade de gênero}

Para se compreender a relação entre desenvolvimento, meio ambiente e o desafio da igualdade de gênero, inicialmente, recorre-se a Karl Marx para explicitar a relação metabólica entre os seres humanos e a natureza:

[...] o homem vive da natureza, isto é, a natureza é o seu corpo, e ele precisa manter com ela um diálogo continuado para não morrer. Dizer que a vida física e mental do homem está vinculada à natureza significa simplesmente que a natureza está vinculada a si mesma, pois o homem é parte da natureza.

Embora Marx expressasse essa relação abrangendo tanto as 'condições impostas pela natureza' quanto a capacidade dos seres humanos de afetar esse processo e, ainda, outras produções do autor demonstrem profunda preocupação com a produção, com os limites ecológicos e com a existência de uma 'falha metabólica, ${ }^{15}$ a relação do homem com a natureza na sua relação com as questões do desenvolvimento não se constituiu um elemento central da perspectiva marxista até a década de 1970.

A ênfase sobre as denominadas questões ambientais na sua relação com o desenvolvimento econômico emerge no contexto dos anos de 1980, quando, na passagem do longo ciclo expansivo do capitalismo em escala internacional para o ciclo recessivo, o desenvolvimento passou a estar condicionado ao combate à inflação, à indução estatal e à distribuição de renda. Essa posição foi assumida pelo neoliberalismo ao submeter todas as demandas das classes subalternas ao filtro da estabilidade monetária e do 'desenvolvimento'.

No decorrer das décadas subsequentes, consolidou-se a mercantilização das relações econômicas políticas e sociais e se impôs a necessidade de um movimento contrahegemônico de desmercantilização, ou seja, de privilegiar a esfera pública, um processo aberto, objeto de disputa ideológica e política; cujo desfecho, ainda na atualidade, depende das formas organizativas da sociedade e, portanto, também das mulheres.

Foi também na década de 1980 que emergiu a concepção de desenvolvimento sustentável, ${ }^{16}$ estando nela uma ênfase recorrente na autonomia e na autodeterminação

\footnotetext{
${ }^{14}$ MARX, 1974, p. 328.

${ }^{15}$ Expressão utilizada por John Bellamy Foster em A ecologia de Marx - materialimo e natureza (FOSTER, 2010).

${ }^{16}$ Desenvolvimento sustentável, termo inspirado no conceito de ecodesenvolvimento, de lgnacy Sachs, na Conferência Mundial de Meio Ambiente de Estocolmo. O termo foi criado em 1987, pela Comissão Mundial sobre Meio Ambiente e Desenvolvimento (Relatório Brundtland), com o significado de atender às necessidades do presente sem comprometer a qualidade de vida das gerações futuras.
} 
local, regional e nacional, com desdobramentos ideopolíticos, ensejando abordagens tanto progressistas como conservadoras das novas formas de se conceber desenvolvimento, como também diferentes abordagens sobre gestão e qualidade de vida. O termo 'sustentabilidade' refere-se a uma categoria que, pela própria imprecisão, possibilita diferentes apropriações: tanto pode servir para apreender a necessidade de outro modelo de desenvolvimento, como possibilita o discurso neoliberal da sustentabilidade, a partir da valorização da eficiência empresarial e da educação ambiental, sem que esta engendre as contradições do sistema de produção capitalista.

Como sinaliza István Mészáros, ${ }^{17}$ durante muito tempo acreditou-se que todos os problemas humanos seriam felizmente resolvidos através de um 'desenvolvimento' e de uma 'modernização' socialmente neutra e que a tecnologia ultrapassaria todos os obstáculos. Ainda hoje permanecem as esperanças de que se façam correções estritamente tecnológicas, mesmo quando estas colidem diretamente com os interesses da sobrevivência da própria humanidade. A busca pelo crescimento econômico, sem restrições ao capital financeiro e produtivo, reitera a acumulação de problemas às futuras gerações. Existe uma relação interdependente entre crescimento e desenvolvimento, sendo que ambos merecem ser motivo de uma análise crítica que as discussões sobre gênero não podem ignorar e/ou abordar tangencialmente.

Mészáros propõe "[...] a necessidade de qualificar todo o desenvolvimento futuro como desenvolvimento sustentável, de modo a construir o conceito com um conteúdo realmente factível e socialmente desejável". ${ }^{18}$ Definindo sustentabilidade, o autor assim expressa:

[...] significa o estar realmente no controle dos processos culturais, econômicos e sociais vitais através dos quais os seres humanos não só sobrevivem, mas também podem encontrar satisfação, de acordo com os objetivos que colocam a si mesmos, em vez de estarem à mercê de imprevisíveis forças naturais e quase-naturais determinações socioeconômicas. A ordem social existente é edificada no antagonismo estrutural entre o capital e o trabalho, requerendo, portanto, o exercício de um controle externo sobre todas as forças insubmissas. A adversidade é o acompanhante necessário de tal sistema, não interessando quão elevados são os desperdícios humanos e econômicos para a sua manutenção."

O caráter adverso do sistema de produção e reprodução capitalista, para as classes subalternas e para a natureza, principalmente no caso brasileiro, tem que ser enfrentado, daí a razão por que a questão da igualdade substantiva não pode ser evitada nos tempos atuais, como o foi no passado. As considerações desse autor são importantes, pois sustentam o nexo entre as determinações da condição social brasileira, a desigualdade material e a forma como estas são reforçadas por homens e mulheres que interiorizam o seu 'papel na sociedade', mais ou menos consensualmente, sujeitando-se aos que tomam decisões sobre as suas vidas. Essa cultura foi constituída em paralelo com a formação das novas estruturas de desigualdade do capital, sobre as fundações iníquas do passado. Houve uma interação recíproca entre as estruturas reprodutivas e a dimensão cultural, criando uma convergência que prendeu cada indivíduo no seu estritamente contido domínio de ação.

Ao se recuperar a trajetória recente das análises sobre as chamadas questões socioambientais, identifica-se que Ronaldo Coutinho ${ }^{20}$ faz uma abordagem crítica da

17 MÉSZÁROS, 2001, p. 6

${ }^{18}$ MÉSZÁROS, 2001, p. 8

19 MÉSZÁROS, 2001, p. 8

${ }^{20}$ COUTINHO, 2009, p. 21. 
chamada 'crise ambiental', baseada nas concepções que defendem a possibilidade da criação de práticas econômicas e sociais alternativas capazes de operar transformações expressivas nas relações entre sociedade e meio ambiente, à luz do paradigma do 'desenvolvimento sustentável', com a internalização de uma nova ética, mediante o surgimento de uma 'consciência ecológica'.

De igual forma, para Coutinho, o exame mais atento da noção de desenvolvimento sustentável evidencia que ele significaria, ao mesmo tempo, o desenvolvimento de um país (ou região) baseado em suas próprias potencialidades, isto é, endógeno, realizado de forma compatível com a gestão ecologicamente equilibrada. Além disso, esse 'novo' modelo de desenvolvimento seria lastreado por uma nova ética, na qual os objetivos econômicos seriam subordinados ao funcionamento dos ecossistemas e aos parâmetros da qualidade de vida das pessoas. Há, portanto, segundo o autor, dois aspectos, pelo menos, a destacar: o primeiro diz respeito à contradição de se propor um modelo endógeno de desenvolvimento exatamente num momento histórico marcado pela mundialização do capital financeiro e pela globalização; e o segundo diz respeito à formulação capaz de resolver o problema da almejada subordinação dos interesses e das ações da economia de mercado à gestão dos recursos naturais referentes à qualidade de vida das pessoas.

No entendimento de Coutinho, essas abordagens, independentemente do caráter multissetorial - assumido pelo movimento ambientalista, desde os anos de 1980, e do desenvolvimento de estudos e ações que visam à proteção do meio ambiente -, enveredam para uma formulação ideológica e politicamente voltada para a construção de uma verdadeira utopia liberal de justiça socioambiental que, em última instância, realizar-se-ia no próprio âmbito da lógica mercantil do modo de produção capitalista. Trata-se, segundo o autor, de um reformismo aparentemente ingênuo.

Por sua vez, François Chesnais e Claude Servatii ${ }^{21}$ enfatizam a base oligopolista sobre a qual repousa a estratégia do capital financeiro, transferindo as atividades industriais dos grupos multinacionais para países que combinam baixos custos salariais, mão de obra frequentemente qualificada e, se possível, uma demanda interna de dimensão importante. Em outros países, a exploração dos recursos naturais permanece como o maior objetivo do capital.

Pronunciando-se sobre o tema, Michael Lowy ${ }^{22}$ aponta a questão ecológica como o principal fator impulsionador de uma renovação teórica na tradição marxista. O autor propugna uma economia de transição para o socialismo, incorporando o meio ambiente social e natural; transição baseada na escolha democrática das prioridades e dos investimentos pela própria população e não pelas 'leis do mercado'.

Mary Garcia Castro e Miriam Abramovay enfatizam que, no discurso da conservação, tem prevalecido "[...] uma perspectiva puramente biológica, sem considerar a relação que os homens e as mulheres e suas distintas formas de organização estabelecem com o seu entorno". ${ }^{23}$ Nas palavras das autoras, "[...] nos referimos às relações que estabelecem os seres humanos entre si e com os outros entes da natureza, através de criações mais simples, ou elaboradas, ou mesmo contraditórias, como no contexto da sociedade mais ampla". ${ }^{24}$ Em seus estudos, as autoras enfatizam a influência do enfoque conservacionista na problemática ambiental, mas afirmam que essa corrente de pensamento limitou-se a colocar as soluções alternativas para o problema ambiental, sem considerar que, em muitos casos,

${ }^{21}$ CHESNAIS E SERVATI, 2003.

22 LOWY, 1999 e 2000.

${ }^{23}$ CASTRO E ABRAMOVAY, 1997, p. 36

${ }^{24}$ CASTRO E ABRAMOVAY, 1997, p. 36. 
esse é um sintoma de uma problemática mais ampla, que não se aborda, e que engloba problemas econômicos, sociais e políticos.

Um aspecto que merece atenção é o indicativo de que, ao se abordar o tema, devese pensar em quem deve, como e por que deve conservar ou não determinados recursos; caso contrário, poder-se-á fazer suposições ou generalizações de pouco valor para a compreensão e intervenção na realidade.

Quando se faz referência ao meio ambiente, a intenção é de compreender e relacionar processos da natureza à ação humana. Em última instância, concorda-se com Abramovay ${ }^{25}$ de que não se trata de conhecer processos sociais e da natureza de forma isolada, mas de saber de que maneira o uso que diferentes grupos sociais fazem dos recursos existentes interfere em processos da natureza que afetam a qualidade de vida dos homens e das mulheres; e de saber quais formas alternativas de utilização são possíveis para que os impactos negativos de desenvolvimento sejam evitados ou minimizados. E, com isso, reitera-se a importância de que as questões de gênero sejam incluídas como questões transversais a essa discussão.

A situação das mulheres passou por avanços importantes nas últimas duas décadas, mas estes não foram homogêneos no tempo e no espaço, pois ainda persistem desigualdades significativas que constituem um obstáculo para a igualdade substantiva. Entretanto, a luta das mulheres contra os preconceitos de classe, gênero, raça/etnia vem desenhando novos contornos para a ação política feminista, enriquecendo tanto a discussão da questão de gênero quanto a questão das mulheres em face das situações de desastres socioambientais.

\section{Uma agenda de pesquisa e de ação: a título de considerações finais}

Apreender as questões que envolvem desenvolvimento, desastres socioambientais e gênero requer objetivos e compromissos em torno de um projeto societário.

Uma agenda de pesquisa e de ação deverá incluir os aspectos sociais, econômicos, políticos e culturais, o que remete à busca por respostas a múltiplas questões, dentre as quais se destacam algumas.

Os países 'subdesenvolvidos' 'dependentes' ou 'periféricos' podem alterar o quadro de miséria, desorganização espacial, problemas de educação, saúde, segurança sem degradar seu meio ambiente? Ou, então, em busca do desenvolvimento, devem reivindicar o direito de consumir, poluir, destruir, pelo modelo de países centrais? Como e de que forma as relações de gênero, os padrões de desenvolvimento, as mudanças do meio ambiente afetam as mulheres e os homens e os expõem aos impactos de desastres socioambientais? Diante das perdas e dos danos, como as mulheres, em contextos específicos, estão organizadas politicamente a fim de contribuírem para a preservação do meio ambiente, a prevenção dos desastres socioambientais e a recuperação face à sua ocorrência?

Para superar essas questões, entende-se que é preciso desenvolver uma estratégia de gênero, investir em pesquisas específicas sobre sua relação com desenvolvimento, com a preservação da natureza e com os desastres socioambientais.

É importante também estabelecer um sistema para o uso de indicadores e critérios sensíveis ao gênero, a fim de que os governos os utilizem no processo de planejamento, execução e avaliação das políticas sociais em uma perspectiva transversal.

\footnotetext{
${ }^{25}$ ABRAMOVAY, 1993 apUd CASTRO e ABRAMOVAY, 1997.
} 
Faz-se necessário, da mesma forma, analisar e identificar os impactos específicos sobre o gênero e as medidas de proteção relacionadas com inundações, secas, ondas de calor, doenças e outras mudanças e desastres socioambientais; e, dado que milhões de mulheres pobres afetadas pela mudança climática vivem e trabalham fora do alcance dos mercados formais, urge desenhar e implementar mecanismos de financiamento acessíveis a elas para reduzir suas necessidades.

Além disso, incluir a interação 'desenvolvimento, natureza e gênero' em uma agenda que construa uma contra-hegemonia à relação 'sociedade e natureza', pois qualquer política para reparar ou reduzir os efeitos dessa relação - inclusive nos desastres socioambientais - dificilmente ajudará as mulheres subalternizadas; contudo, se ressalta a importância de as propostas serem encaminhadas e apreendidas pelas organizações nacionais e, também, internacionais.

Considerando que se identifica a falta da perspectiva de gênero na prevenção e na resposta às situações de desastres socioambientais, bem como a falta de diálogo entre os gestores e os profissionais sobre o modo como as questões socioambientais mantêm uma imbricada relação com as questões de gênero, sugere-se, também, outro olhar sobre a participação das mulheres ou sobre o objetivo de possibilitar às mulheres acesso aos centros decisórios. Esse novo olhar e posicionamento político deve partir de experiências concretas, decorrentes da experiência do desastre, visando não reiterar a inserção das mulheres apenas como 'objetos' dos programas, mas também como gestoras destes. Dessa forma, elas estarão menos sujeitas às práticas que reiteram desigualdades, discriminações e violências, contidas em ações localizadas, programas de intervenção emergenciais, que não contemplam um conhecimento profundo, prospectivo, inovador e interdisciplinar.

Atualmente há diferentes abordagens sobre gênero e a participação das mulheres no processo de prevenção e de respostas às situações de desastres. Contudo, duas tendências se apresentam. A primeira indica uma participação a partir de uma gestão 'municipalistaecologista', que privilegia mudanças atitudinais por parte da denominada 'comunidade' e ressalta a importância do município na atenção às situações de desastre socioambientais. A segunda tendência, que tem como enfoque a 'participação-desenvolvimento social', sustenta-se na participação social, em uma perspectiva emancipatória e questiona a relação da sociedade com a natureza, as bases em que se estrutura o sistema capitalista e, consequentemente, as causas e respostas aos desastres socioambientais.

O que é possível e necessário indicar é a importância de se elaborar uma agenda de pesquisa e de ação transversal entre gênero, desenvolvimento e desastres socioambientais, para a produção de um conhecimento que instrumentalize a ação necessária e possível.

\section{Referências bibliográficas}

ARMSTRONG, Sue. "Climate Change: Ask the Experts" ("Cambio climático: preguntarles a los expertos"). NewScientist.com. 2001. Disponível em: <http://www.newscientist.com/ hottopics/climate/climate.jsp?id=23154500>. Acesso em: 8 maio 2010.

CASTRO, Mary Garcia; ABRAMOVAY, Miriam. Gênero e meio ambiente. São Paulo: Cortez Editora, UNESCO, UNICEF, 1997.

CHESNAIS, Francois; SERFATI, Claude. "Ecologia e condições físicas da reprodução social: alguns fios condutores marxistas." Crítica Marxista, n. 16, p. 39-75, mar. 2003.

COUTINHO, Ronaldo. "'Crise ambiental' e desenvolvimento insustentável: a mitologia da sustentabilidade e a utopia da humanização do capitalismo 'selvagem'". Revista Praia Vermelha, Rio de Janeiro, v. 19, n. 2, p. 21-36, jul/dez., 2009. 
FOSTER, John Bellamy. A ecologia de Marx - materialimo e natureza. 2. ed. Rio de Janeiro: Civilização Brasileira, 2010.

FREITAS, Rosana C. M.; MARQUES, Cristiane C. "Serviço Social: fios condutores para a prevenção e atendimento de ocorrência de eventos extremos". In: CONGRESSO BRASILEIRO DE ASSISTENTES SOCIAIS, 12, 2010, Brasilia. Anais... Brasília, 2010. p. 1-14.

LOWY, Michel. "De Marx ao ecossocialismo". In: SADER, Emir; GENTILLI, Pablo (Orgs.). Pósneoliberalismo II - que Estado para que democracia? Vozes. Petrópolis, 1999.

LOWY, Michel. "A dialética marxista do progresso". In: LOWY, Michel; BENSAïD, Daniel. Marxismo, modernidade e utopia. São Paulo: Xamã, 2000.

MARX, Karl. Erly Writings. New York: Vintage, 1974.

"Manuscritos econômicos e filosóficos e outros textos escolhidos". In: Os Pensadores Marx I. 4. ed., São Paulo: Nova Cultural, 1987. v. 1.

MÉSZÁROS, István. O desafio do desenvolvimento sustentável e a cultura da igualdade substantiva. Caracas: Cúpula dos Parlamentos Latino-Americanos, 2001.

ONU, Convenção-Quadro das Nações Unidas sobre a Mudança do Clima. Brasil, 1992.

SCOIT, Russell Parry. "Ruralidade e mulheres responsáveis por domicílios no Norte e no Nordeste". Revista Estudos Feministas, v. 15, n. 2, 2007. Disponível em: <http://www.scielo.br/ scielo.php? script $=$ sci_arttext\&pid $=$ S0104-026X2007000200009\&Ing $=$ pt\&nrm $=$ iso $>$. Acesso em: 10 jun. 2010.

TRANTER, Kellie. Mulher e mudanças climáticas. 2008. Disponível em: <http:// miradaglobal.com/index.php?option $=$ com_content\&view $=$ article\&id $=837:$ mujer-ycambio-climatico\&catid=32:ecologia\&ltemid=36\&lang=pt> Acesso em: 12 maio 2010.

[Recebido em agosto de 2010 e aceito para publicação em outubro de 2010]

\begin{abstract}
The Construction of an Agenda Concerning Gender, Socio-Environmental Disasters, and Development

Abstract: The purpose of this essay is to discuss issues related to development, socioenvironmental disasters, and gender, which, for being important elements of the public debate in Brazil today, should be addressed in research and public policy strategies. The relationship between gender, class, race/ethnicity and socio-environmental disasters is presented, and key concepts about development, the environment, and equality are examined in the context of recent economic policies. The essay reflects on the condition of women found in a subaltern condition in capitalist society who suffer the consequences of socio-environmental disasters. It concludes with suggestions for including a focus on gender in the preparation of research and action strategies.
\end{abstract}

Key words: Nature; Society; Development; Disasters; Women. 